\title{
Magnetic and Very Low Frequency Electromagnetic (VLF-EM) investigations for gold exploration around Ihale in Bunnu-Kabba Area of Kogi, north-central Nigeria
}

\author{
Olawale Olakunle OSINOWO*, Michael Oluseyi FALUFOSI \\ Department of Geology, University of Ibadan, Ibadan, Nigeria; \\ e-mail: wale.osinowo@ui.edu.ng, olawale.osinowo13@alumni.imperial.ac.uk; \\ tel.: +234 (0) 8124109193
}

\begin{abstract}
This study integrates ground magnetic and Very Low Frequency Electromagnetic (VLF-EM) methods of geophysical investigation to probe the subsurface in terms of rock magnetic susceptibility and ground conductivity for the purpose of identifying mineralized pegmatite veins that could serve as host for gold and associated metallic deposits. Twenty five (25) carefully planned ground magnetic and VLF-EM profiles, each, were occupied east and west of a reference profile which was purposively established on an identified mineralized pegmatite vein around Ihale in Bunnu-Kabba area of Kogi, northcentral Nigeria. The acquired ground magnetic data were filtered and Reduced To Pole at Low Latitude (RTPLL) to remove regional field effect, cultural noise as well as focus the peaks of magnetic anomalies over corresponding sources. The measured raw real and raw imaginary components of the EM fields were subjected to Fraser and Karous Hjelt filtering to remove harmonic noise, focus and make anomaly amplitudes relate directly to the causative conductor as well as generate current density employed to characterise the subsurface. Seven (7) zones of relatively high VLF-EM derived current density with matching high residual positive magnetic anomalies present closely correlate-able signatures with subsurface response obtained around the reference profile established where local mining activities indicate evidence of gold and associated metallic mineralization of the pegmatite vein. The delineated zones constitute targets for gold and associated base metal prospects which could be further developed for economic benefit of the community.
\end{abstract}

Key words: electromagnetic survey, ground magnetic survey, gold mineralization, mineralized pegmatite veins, Ihale

${ }^{*}$ corresponding author 


\section{Introduction}

Gold is a precious and economic metal that offers rewarding financial benefit because of its precious quality and stable value. The all time high demand and the rising price of this precious metal has engendered the rush for gold in Ihale and environs in Bunnu-Kabba area of Kogi, north-central Nigeria, where low skilled local miners have built up a mining community to extract gold and other associated metals from a mineralized pegmatite vein. The success of gold extraction recorded from the various tunnels made around the vein created the interest to explore the area in order to identify other mineralized veins that could host gold and other associated metals around the study area and thus provide useful information for better organized extraction of the resource to generate tax and employment for the development of the area.

Geophysical survey is known to generate subsurface image that presents distribution of measured physical parameter(s) along the occupied profile stations and could generate 3D subsurface model where the geophysical technique sampled progressively deeper sections of the subsurface, and the data gathering done along several carefully established parallel profiles. Magnetic and Electromagnetic geophysical methods offer cheap and rapid means of gathering subsurface information about rock's magnetic susceptibility and conductivity (Nabighian, 1991; Osinowo and Olayinka, 2013; Smith, 2014; Lymburner and Smith, 2015). Magnetic susceptibility of rocks plays dominant influence on the intensity and inclination of the induced field generated when rocks response to the earth ambient field (Barnett, 1976). Variation in rock conductivity on the other hand is apt at delineating zones of preferential water saturation or occurrence of base metal deposits which often aid easy flow of current in the subsurface (McNeill, 1990; Osinowo and Olayinka, 2012). Careful selection of profiles that run perpendicular to the general trend of veins around the study area as well as purposive establishment of a profile as a reference profile on an established mineralized vein and the subsequent establishment of other profiles east and west of the reference profile aid identification of other pegmatite veins that could host gold and associated metallic deposits. 


\section{Geology of the Study Area}

The study area is situated in Ihale, a settlement located few kilometres from Bunnu-Kabba area of Kogi in central Nigeria. The geology of Ihale and environs has been severally discussed to be part of the geology of south-western Nigeria which has been well described by Oyawoye (1972), Grant (1978), Rahaman (1988) and others. The study area consists of two main rock types which covers the area in almost equal proportions, Basement Complex rocks in the west and sedimentary rocks to the east (Fig. 1). The basement crystalline rocks include undifferentiated Basement Complex rocks which has been identified to be predominantly migmatite gneiss (comprising of augen gneiss or porphyroblastic granite and biotite gneiss) and intruded by NESW trending pegmatite dykes. Other common rocks include Older Granite of plutonic series of Pan African (650 Ma) tectonic events and undifferentiated meta-sediment identified as low grade schists (Odeyemi, 1977). The major lithology in the sedimentary terrain is sandstone, with some shale,

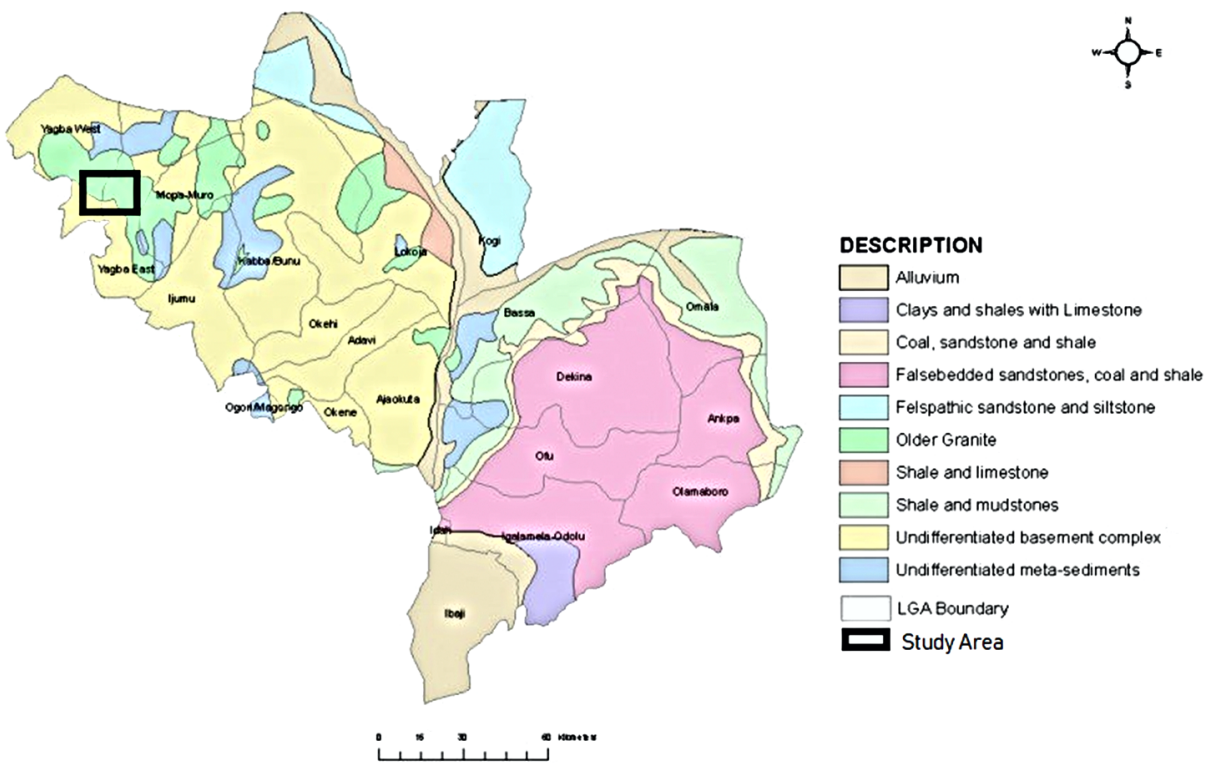

Fig. 1. Geological map of the Kogi State, North Central Nigeria; insert study area (NGSA, 2009). 
limestone, clay and recent alluvium. The sandstones are mostly false-bedded and also contain inter-beds of coal and shale formations.

Structural imprints commonly visible on exposed rocks include foliation, namely: gneissosity, schistosity, and migmatitic banding which indicate rock strain, metamorphic differentiation and recrystallization, suggesting prolonged period of tectonic activities. Other visible structural signatures include minor faults, joints, fractures and pegmatitic intrusions emplaced within fractured zones that trend roughly NW-SE (Ajibade, 1976). Field evidence indicate that the pegmatites are usually granitic or granodioritic in composition with extremely coarse quartz, muscovite and feldspars grains. The pegmatite veins ranges in thickness (width) from $>1 \mathrm{~m}-10 \mathrm{~m}$ and sometimes measure more than $100 \mathrm{~m}$ in length. Pegmatites that intrude the granitic and schistose rocks around Ihale are mostly mineralized and often play host to economic minerals.

\section{Materials and Methods}

In this study two different geophysical investigation methods were integrated to probe the subsurface in order to delineate regions of the subsurface having mineralized veins that could serve as host for gold deposit. Two geophysical parameters were employed in this study to characterise the subsurface and they include the magnetic and the electrical properties of the earth. The magnetic method probed the subsurface in terms of magnetic elements present in metalliferous veins which based on magnetic susceptibility of different rocks delineates veins with gold mineralization. Electromagnetic method on the other hand measure ground conductivity or resistivity its inverse and due to the relative ease of electrical conduction across a mineralized vein is able to map occurrence of mineralized veins in the subsurface (Dobrin and Savit, 1988; Eze et al., 2004; Osinowo et al., 2011).

Ground magnetic measurements were taken using proton-precession magnetometer which consists of a simple sensor made up of a flask containing a proton-rich liquid (such as kerosene or water) unto which a magnetizing solenoid and detector coil are wound. The proton-precession magnetometer makes use of the small magnetic moment of the hydrogen nucleus (proton) to measure the precession of the proton atom to the earth magnetic field 
after the current in the magnetizing solenoid coil is switched off. The measured Total Magnetic Intensity data (TMI) in nanotesla (nT) which records both the regional and the local geologic effect across the occupied profile were quality checked for spurious magnetic data such that bear no significance to the local geology. The resultant TMI data were filtered to remove out ranged, especially high frequency noise that could be attributed to cultural effects such as electric cables and surrounding metallic objects. Low pass Guassian filter was applied to remove the regional and ambient field effects. The residual magnetic data were further reduced to pole at low latitude to simplify the complex magnetic anomalies which usually characterises mid-latitude magnetic data. Here the magnetic anomalies are usually asymmetrically positioned over their causative sources due to low magnetic inclination effects at mid latitudes (Pearson and Skinner, 1982; Keating and Zerbo, 1996; Zhang and Marangoni, 2013). The resultant magnetic data were further filtered using Cosine roll filter to smoothen the data and remove any data processing artefact that may be introduced due to the application of other filters.

Measurement of ground conductivity to delineate mineralized veins, which often presents significantly higher conductivity value than the rocks that host them, was undertaken using ABEM WADI VLF-EM meter. The meter is apt at measuring terrain conductivity by determining the ratio of the real $(\mathrm{Re})$ to the imaginary $(\mathrm{Im})$ components of the propagating time varying low frequency $(15-25 \mathrm{KHz})$ primary $(\mathrm{Hp})$ (originating from far distant transmitting station) EM field and secondary (Hs) EM field generated when eddy current flow in subsurface conductor or conducting zone. The measured difference in field intensity and phase lag between the primary and the secondary EM field is related to the ground conductivity where a phase lag of the secondary EM field relative to the primary EM field of about half a period $\left(180^{\circ}\right)$ indicate a conducting ground, while a resistive ground (poor conductor) will cause the secondary EM field to lags the primary EM field by $90^{\circ}$ (Palacky, 1987; Ogilvy and Lee, 1991).

The acquired data were quality checked (QC) to eliminate noisy data and thereafter subjected to Fraser (1973) filtering to generate the filtered equivalent of the raw real and the imaginary components whose anomaly peaks directly overlie the causative sources and the anomaly amplitude directly relate to the causative conductors (McNeill and Labson, 1991). The filters also 
reduce harmonic and nonlinear noise types commonly associated with power line harmonic radiations, Global System Mobile (GSM) telecommunication transmitters and global lightening (Park and Helliwell, 1978). Subsequently the filtered data were subjected to Karous and Hjelt (1983) filtering which based on the concept that VLF-EM anomalies are caused by galvanic current response from conductive targets within the earth, transformed the measured in-phase component of the EM field into current densities at constant depths (McNeill and Labson, 1991). The VLFPROS MATLAB code for processing VLF-EM data developed by Sundararajan et al. (2006) was employed to apply Karous and Hjelt (1983) and thus generate 2-D pseudosection of current density $\left(\mathrm{mA} / \mathrm{cm}^{2}\right)$ across the surveyed profiles.

Both the magnetic and electromagnetic data were collected through twenty five (25) occupied profiles which run N-S of the study area (Fig. 2). The profiles were established east and west of the reference profile at $50 \mathrm{~m}$ inter profile interval. The reference profile was established on a mineralized vein with evidence of gold mineralization, judging from thriving gold mining activities on the vein. Nine (9) profiles were established east (50E to 450E) of the reference profile, while fifteen (15) profiles (50W to $750 \mathrm{~W}$ ) were occupied west of the reference profile (Fig. 2). The profile range in length from 70 to $125 \mathrm{~m}$ and measurements were taken at $5 \mathrm{~m}$ station interval.

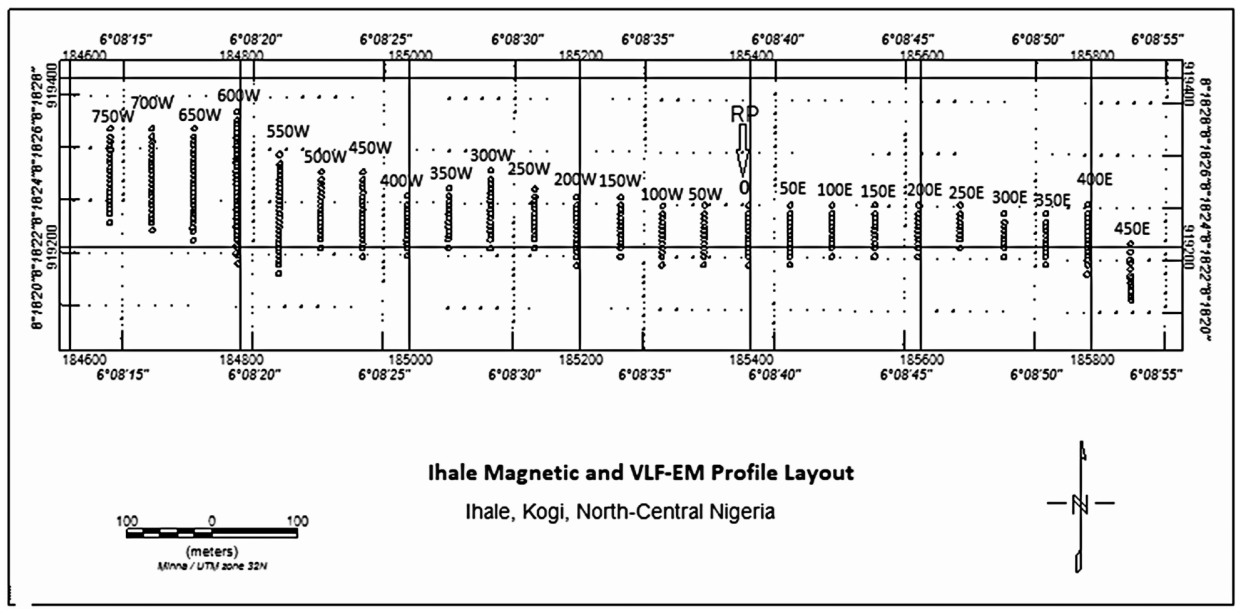

Fig. 2. Ground Magnetic and VLF-EM profile layout across the study area $(\mathrm{RP}=\mathrm{Ref}-$ erence Profile). 


\section{Results and Discussion}

The results of the ground magnetic and VLF-EM surveys carried out for the purpose of delineating mineralized veins that could host gold deposit around Ihale in Bunnu-Kabba area of Kogi, central Nigeria are presented as 2D magnetic distribution map, 2D VLF-EM current density profile sections and 3D subsurface current density model which show the distribution of magnetic intensity and VLF-EM derived current density along the occupied profiles as well as across the study area respectively. Total magnetic intensity map of the study area is presented in the Fig. 3. The map shows the magnetic intensity due to both regional and residual magnetic fields, that is, the core or ambient field effect, as well as intensity of induced magnetic field generated by high magnetic susceptible rocks upon interacting with the earth inducing magnetic field. The residual magnetic intensity map obtained after removing regional magnetic field, filter out cultural noise, simplified and centred magnetic anomalies over causative sources is presented in Fig. 4.

The residual magnetic map indicates regions with high positive and negative amplitude anomalies as well as some medium to low positive and negative amplitude anomalies. High amplitude positive anomalies correspond to regions with relatively high magnetite rich rocks having high magnetic susceptibility (Hunt et al., 1995). Some of the regions that present relatively high magnetic intensity value coincide with identified mineralised pegmatite

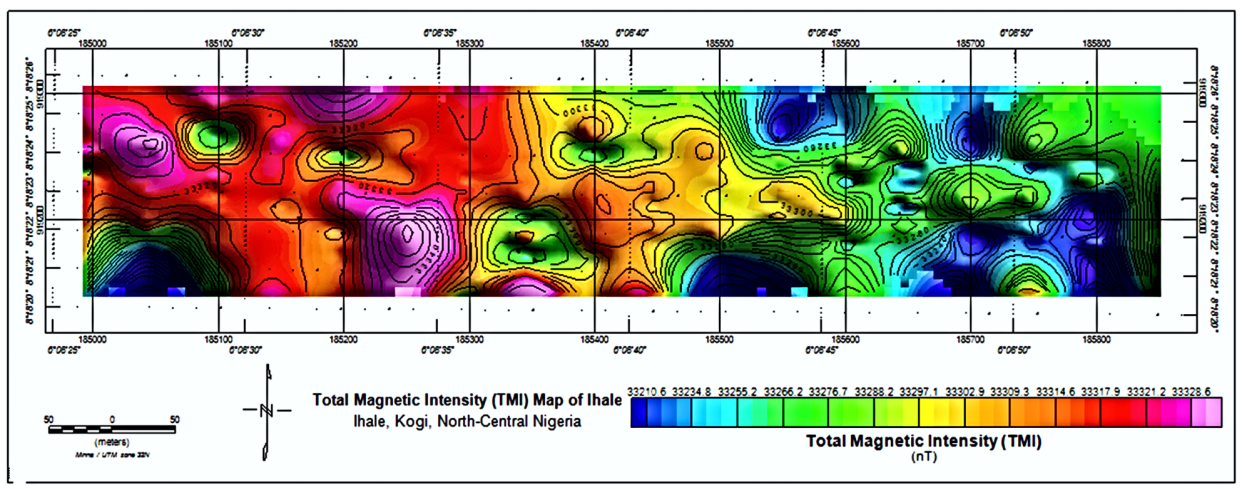

Fig. 3. Total Magnetic Intensity (TMI) Map of the study area. 


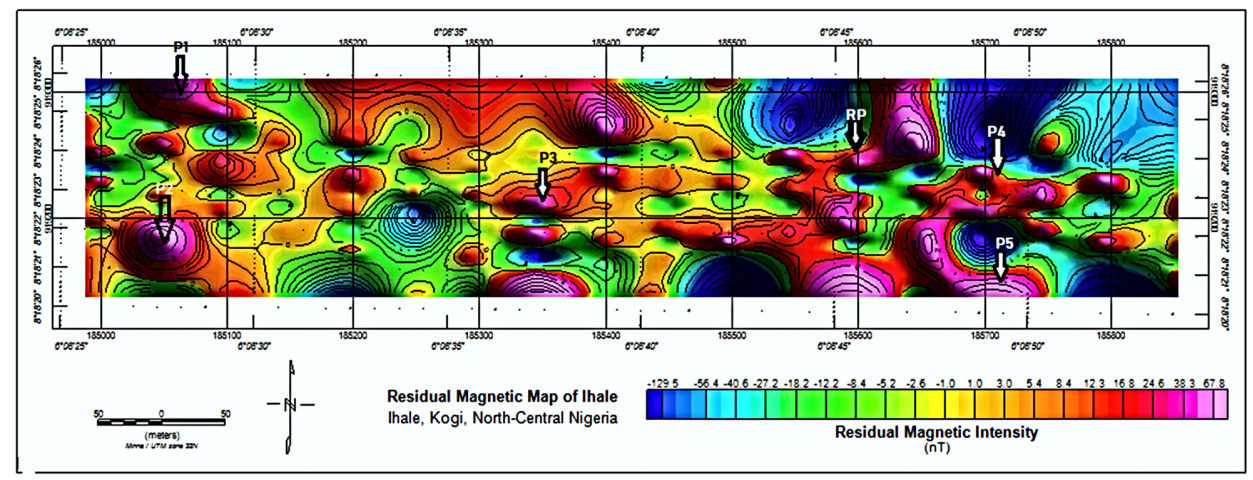

Fig. 4. Residual Magnetic map of the study area.

veins. For example, high magnetic intensity signature around the reference profile (RP arrow) coincide with pegmatite vein that triggered this survey, where local mining activities confirmed that the pegmatite vein is mineralised with base metals ores or metallic deposits of sphalerite, galena and gold.

Five (5) additional zones (P1-P5) of relatively high magnetic intensity, having magnetic signature similar to the magnetic signature of the reference vein $(\mathrm{RP})$ are noticeable on the residual magnetic intensity map of Ihale. The delineated zones (P1-P5) present magnetic intensity anomaly which dominantly runs $\mathrm{NE}-\mathrm{SW}$ and $\mathrm{E}-\mathrm{W}$ with magnetic intensity values ranging from $45 \mathrm{nT}$ to $68 \mathrm{nT}$. Three (3) of the delineated anomalous zones are situated west of the reference vein (Profile 10, Fig. 2), while the remaining two (2) occur east of the reference vein.

Two dimensional (2D) VLF-EM current density sections generated by applying Karous and Hjelt (1983) filter to the filtered real component of the measured VLF-EM field recorded along the occupied profiles are presented in Fig. $5(\mathrm{a}-\mathrm{c})$. The figures show variation in current density with depth along the profile. The $2 \mathrm{D}$ plots imaged the subsurface in terms of current density distribution and probed up to $40 \mathrm{~m}$, the depth of resolution is directly dependent on profile length. Deeper depths were resolved for long profiles while shallower depths for short length profiles. The current density has a linear relationship with ground conductivity and ranges in value from - 20 to $40 \mathrm{~mA} / \mathrm{cm}^{2}$ across the study area. 


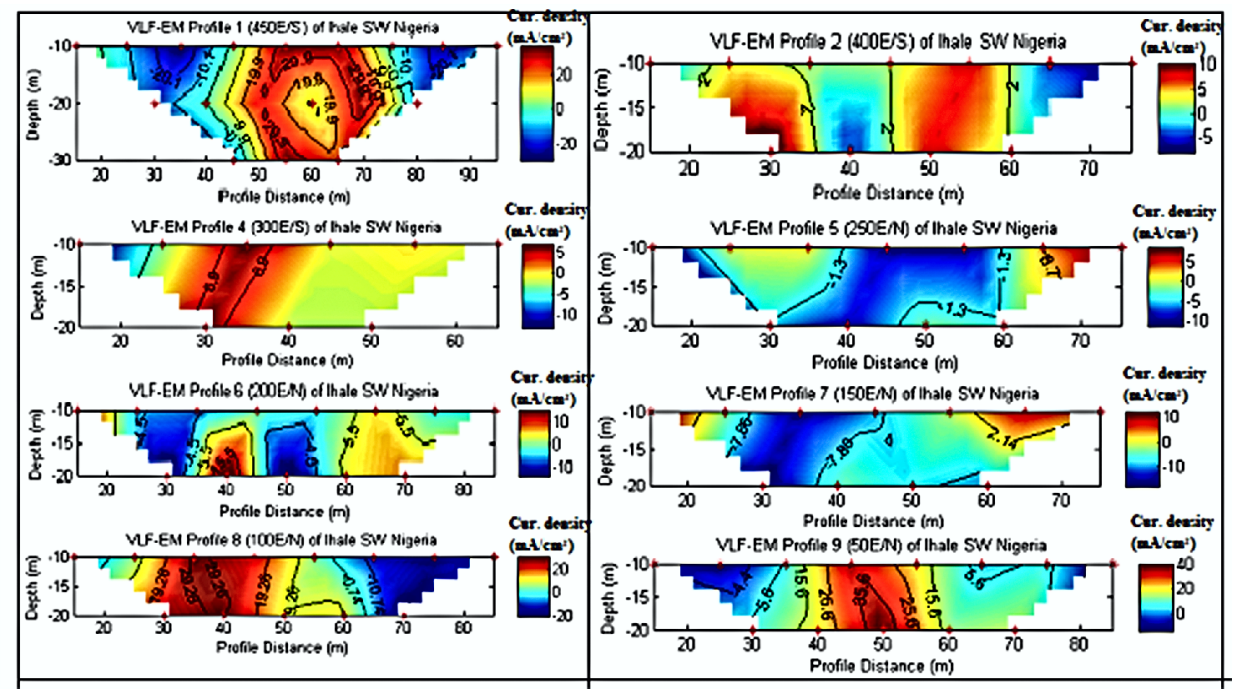

Fig. 5a. 2D VLF-EM current density sections of profile 1-9.

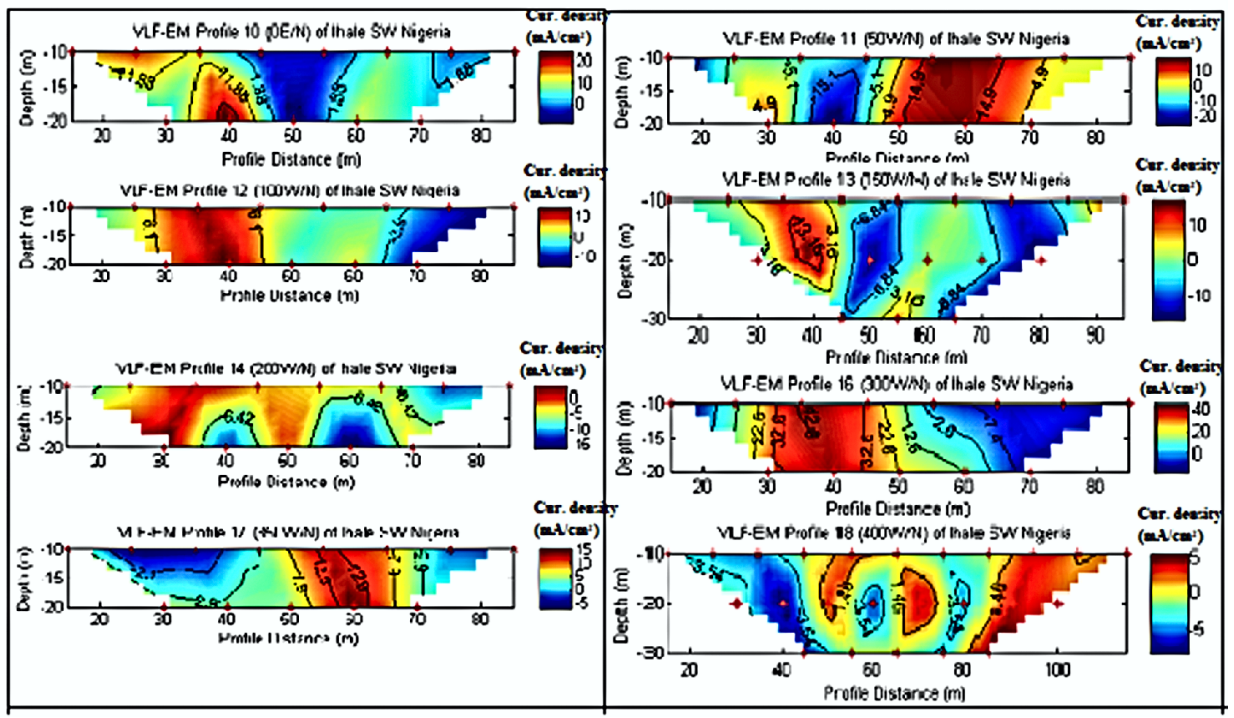

Fig. 5b. VLF-EM current density sections of profile 10-18. 


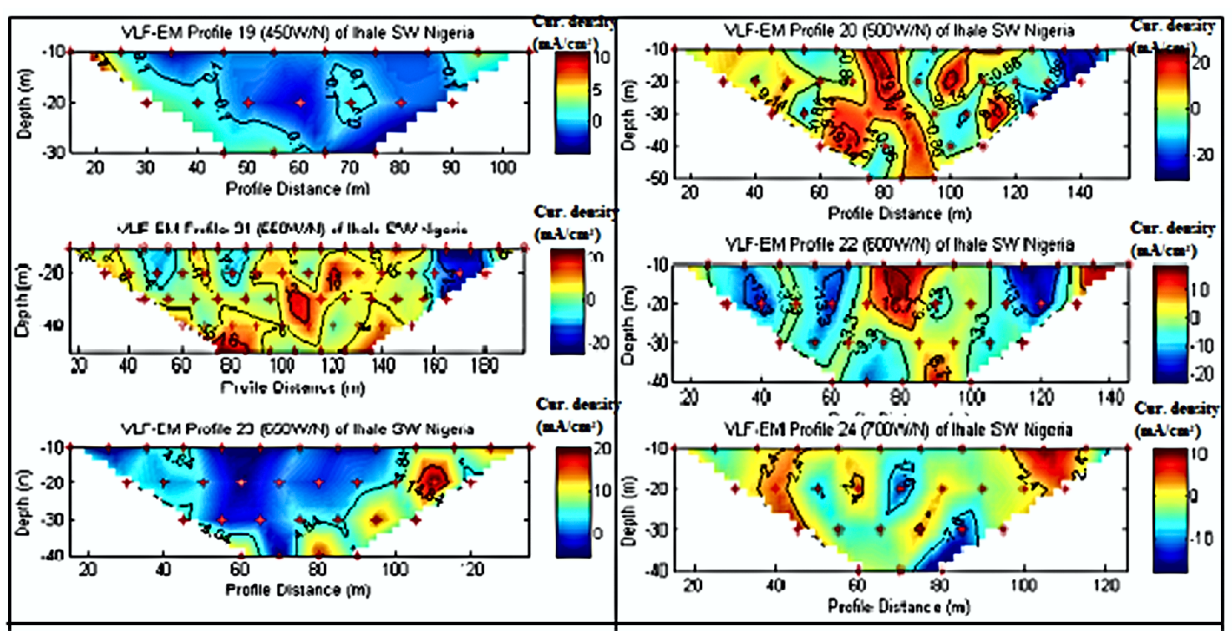

Fig. 5c. VLF-EM current density sections of profile 19-24.

Fig. 5a presents 2D current density of profiles 1 to 9 (with the exception of profile 3 which could not be resolved by the Karous and Hjelt (1983) filter due to very few data points) which were recorded east of the reference profile (Profile 10).

The 2D sections identified some regions of low and high current density values, with high values delineating regions of relatively high conductivity that could be attributed to occurrence of fractured zones and pegmatite veins, while region with low current density values could indicate resistive zones within the basement rocks having little or no fractures. The fractured zones and pegmatite veins are normally zones of high conductivity due to their ability to host water or metallic deposits. Fig. 5 (b \& c) presents the 2D current density distribution section of the reference profile (Profile 10) as well as other profiles occupied west of the reference profile (Profiles 11-24).

The reference profile which was established on a mineralized vein shows relative high current density value (between $10-20 \mathrm{~mA} / \mathrm{cm}^{2}$ ) with the zone of high current density corresponding to the region of active local mining operation on the vein. Most of the delineated relatively high current density zones present a form like veins that are either inclined to the north or south of the profile which runs in north - south direction. Generally, prominent zones of relatively high current density characterise profiles close to the 
reference profile while those occupied farther away present less prominent conductive zones (Fig. 5c).

Three dimensional (3D) display of VLF-EM current density obtained by combining all the VLF-EM results from all profiles across the study area is presented in Fig. 6. It presents the current density distribution along the three orthogonal $(x, y, z)$ directions indicating the variation of the subsurface current density along $\mathrm{N}-\mathrm{S}, \mathrm{E}-\mathrm{W}$ as well as variation with depth, up to $52.2 \mathrm{~m}$. Prominent regions of high and low VLF-EM derived current density are visible on the $3 \mathrm{D}$ subsurface model. The 3D model indicates current density varies from -16 to $20 \mathrm{~mA} / \mathrm{cm}^{2}$ across the study area with some regions of higher subsurface conductivity when compared to the background that presented resistive signatures based on the low current density values.

A section through the $3 \mathrm{D}$ model in the $\mathrm{E}-\mathrm{W}$ direction is presented in Fig. 7 and it indicates the vertical extent of regions of high current density. The figure revealed that some of the regions of relatively high conductivity maintain their conductivity at depth which likely suggests the continuity of the pegmatite veins up to $52 \mathrm{~m}$.

Zones of high current density were isolated using isosurface data clip at 18.5 current density cut-off value for the purpose of identifying zones of characteristically high conductivity that can be related to mineralized peg-

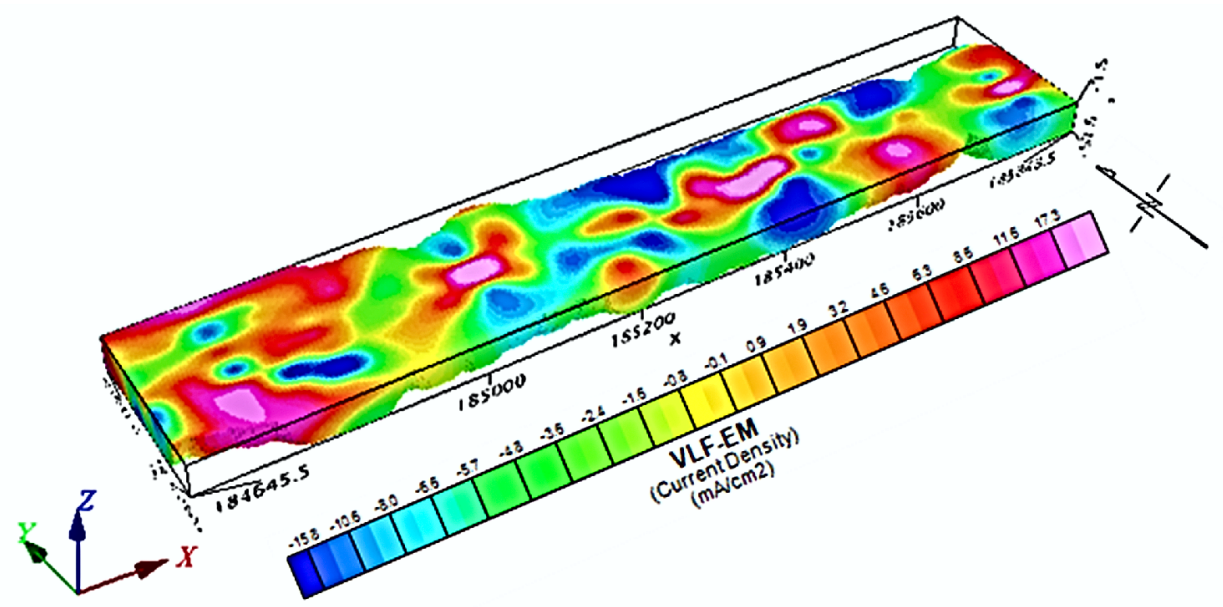

Fig. 6. 3D VLF-EM current distribution model of the surface area. 


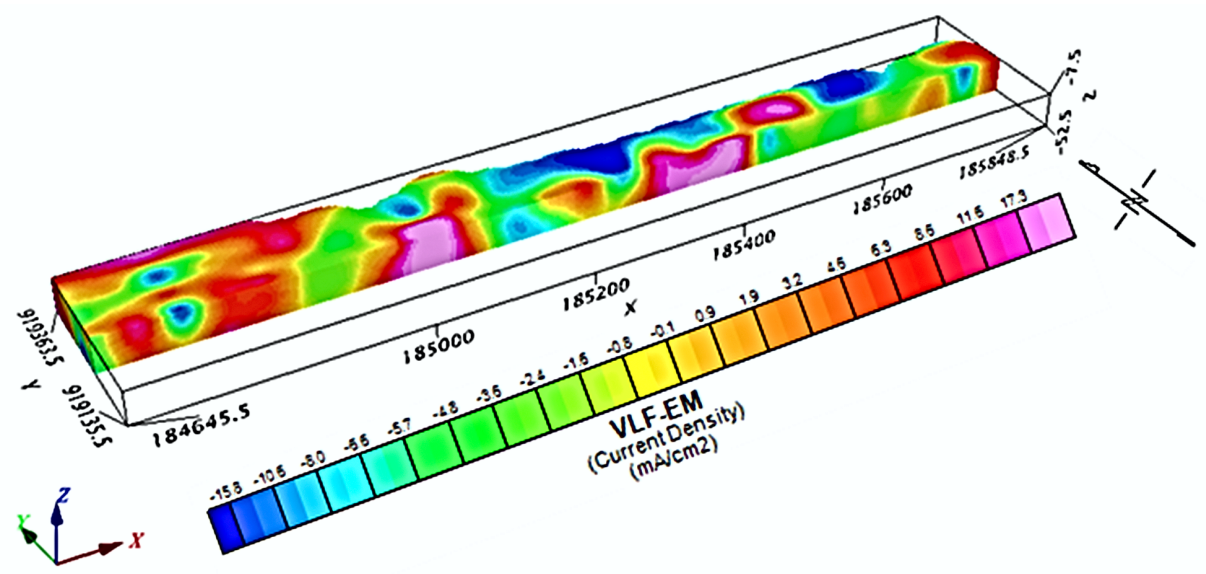

Fig. 7. E-W Section through VLF-EM 3D model of the study area.

matite veins (Fig. 8). Six (P1-P6) candidate zones of high current density $\left(\geq 18.5 \mathrm{~mA} / \mathrm{cm}^{2}\right)$ were identified apart from the one that coincide with the mineralized pegmatite vein (RP) upon which the reference profile was established.

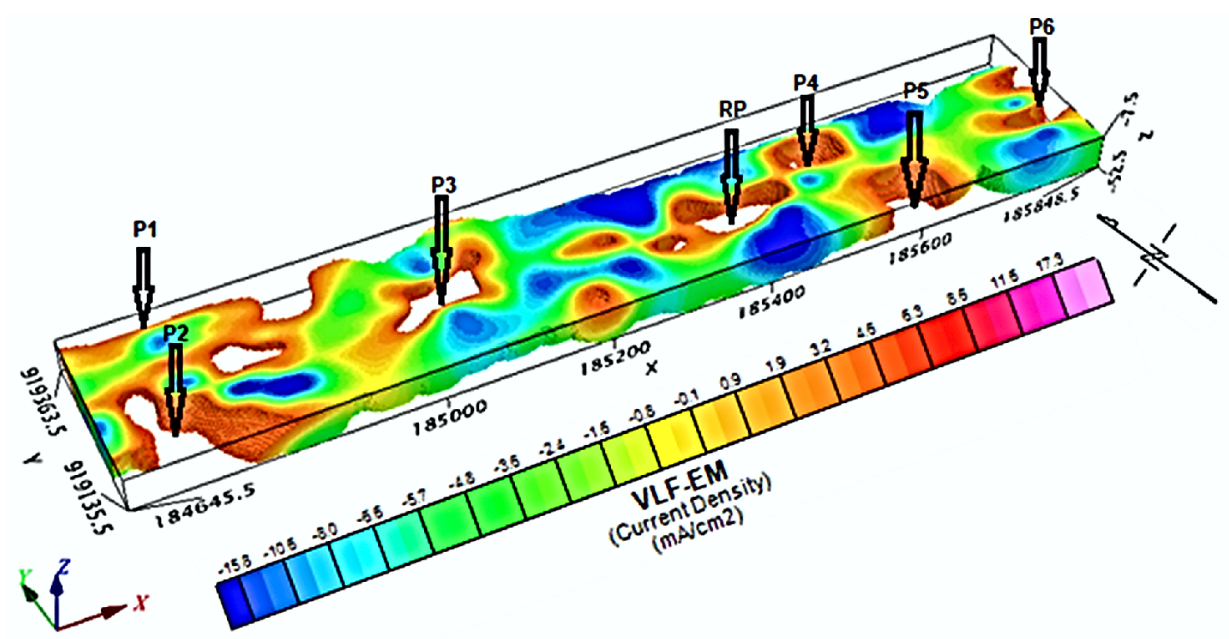

Fig. 8. Isosurface data clip at $18.5 \mathrm{~mA} / \mathrm{cm}^{2}$ current density cut off to delineate zones of high conductivity. 
A careful examination of the generated isosurface current density data clips (Fig. 9), especially when compared with the one generated around the reference profile which was purposively established on pegmatite vein having evidence of gold mineralization in addition to other associated metallic deposits, identified six (P1-P6) other targets having similar current density signature as candidate zones for further confirmatory investigations.

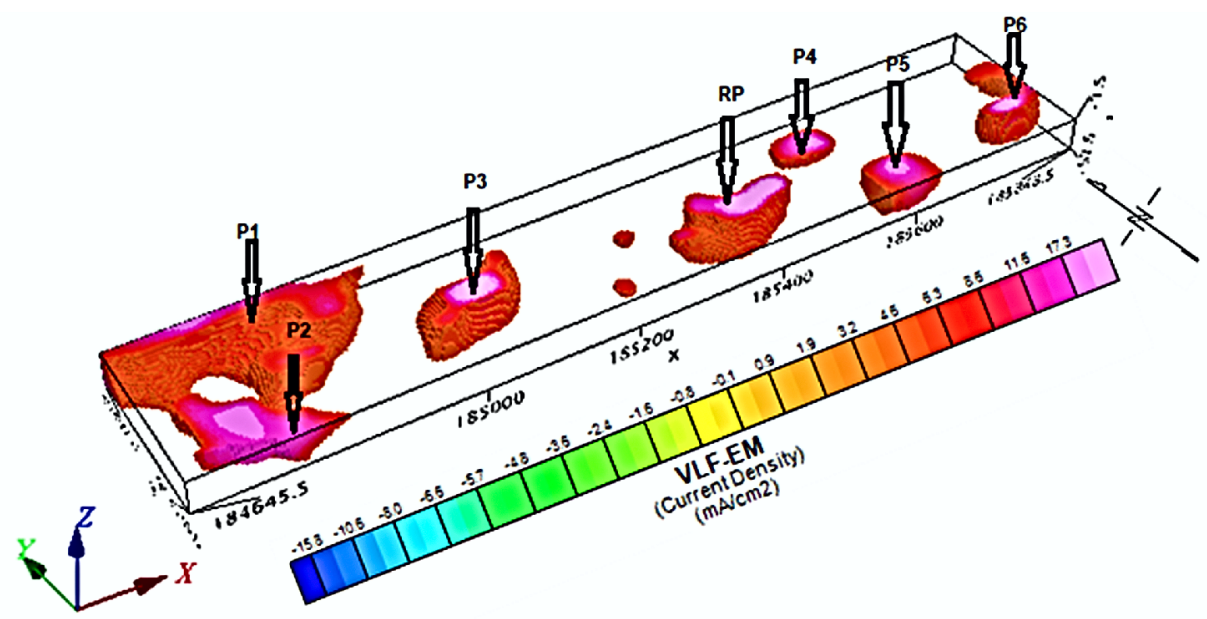

Fig. 9. Generated isosurface current density data clips (at $18.5 \mathrm{~mA} / \mathrm{cm}^{2}$ current density cut off).

\section{Conclusion}

This study highlights the importance of carefully planned ground magnetic and VLF-EM surveys for the purpose of identifying other likely mineralized pegmatite veins situated around a mineralized reference pegmatite vein upon which a measurement survey profile was purposively established. The close correlation between the magnetic and VLF-EM current density signatures between the already established mineralized pegmatite vein and other delineated zones distinguished them as targets for gold and other metallic deposits' prospect development around Ihale in Bunnu-Kabba area of Kogi, north central Nigeria. 
Acknowledgements. The authors are grateful for constructive comments and suggestions of the anonymous referees, their effort helped to improve the quality of the paper.

\section{References}

Ajibade A. C., 1976: Provisional classification and correlation of the Schist belts of Northwestern Nigeria. In: Kogbe C. A. (Ed.): Geology of Nigeria. Elizabethan Pub. Co., Lagos, 85-90.

Barnett, C. T., 1976: Theoretical modeling of the magnetic and gravitational fields of an arbitrarily shaped three dimensional body. Geophysics, 41, 1353-1364.

Dobrin M. B., Savit C. H., 1988: Introduction to Geophysical Prospecting. 4th ed., New York, McGraw-Hill, 867.

Eze C. L., Mamah L. I., Israel-Cookey C., 2004: Very low frequency electromagnetic (VLF-EM) response from a lead sulphide lode in the Abakaliki lead/zinc field, Nigeria. International Journal of Applied Earth Observation and Geoinformation, 5, 159-163.

Fraser D. C., 1973: Magnetite ore tonnage estimates from an aerial electromagnetic survey. Geoexploration, 11, 97-105.

Grant N. K., 1978: Structural distinction between a metasedimentary cover and an underlying basement in the 600 m.y. old Pan-African domain of north-western Nigeria. Bull. Geol. Soc. Am., 89, 50-58.

Hunt C., Moskowitz B. M., Banerje S. K., 1995: Magnetic properties of rocks and minerals. In: Ahrens T. J. (Ed.): Rock Physics and Phase Relations. A Handbook of Physical Constraints. AGU Reference Shelf 3, 189-204.

Karous M. R., Hjelt S. E., 1983: Determination of apparent current density from VLF measurements: Report. Department of Geophysics, University of Oulu, Finland, Contribution 89. 19 pp.

Keating P., Zerbo L., 1996: An improved technique for reduction to the pole at low latitudes. Geophysics, 61, 131-137.

Lymburner J., Smith R. S., 2015: A procedure for collecting electromagnetic data using multiple transmitters and receivers capable of deep and focused exploration. Geophysics, 80, 1, E1-E10, doi: 10.1190/geo2014-0251.1.

McNeill J. D., 1990: Use of electromagnetic methods for groundwater studies. In: Ward S. H. (Ed.): Geotechnical and environmental geophysics, 1, SEG, 191-218.

McNeill J. D., Labson V., 1991: Geological mapping using VLF radio fields. In: Nabighian M. N. (Ed.): Electromagnetic Methods in Applied Geophysics, 2, Society of Exploration Geophysicists, Tulsa, OK, 521-640.

Nabighian M. N., 1991: Electromagnetic methods in applied geophysics 2, SEG.

NGSA, 2009: Geological Map of Nigeria. Nigerian Geological Survey Agency. 
Odeyemi I. B., 1977: On the petrology of the basement rocks around Igarra, Bendel State, Nigeria. Ph. D. Thesis (unpublished), 223 p. Univ. of Ibadan, Nigeria.

Ogilvy R. D., Lee A. C., 1991: Interpretation of VLF-EM inphase data using current density pseudosections. Geophysical Prospecting, 39 567-580.

Osinowo O. O., Akanji A. O., Akinmosin A., 2011: Integrated Geophysical and Geotechnical Investigation of the Failed Portion of a Road in Basement Complex Terrain, Southwestern Nigeria. RMZ - Materials and Geoenvironment, 58, 2, 143-162.

Osinowo O. O., Olayinka A. I., 2012: Very Low Frequency Electromagnetic (VLF-EM) and Electrical Resistivity (ER) Investigation for Groundwater Potential Evaluation in a Complex Geologic Terrain around Ijebu-Ode Transition Zone, Southwestern Nigeria. Journal of Geophysics and Engineering, 9, 4, 374-396.

Osinowo O. O., Olayinka A. I., 2013: Aeromagnetic Mapping of Basement Topography around the Ijebu-Ode Geological Transition Zone, Southwestern Nigeria. Acta Geodaetica et Geophysica, 48, 3, 451-470.

Oyawoye M. O., 1972: The Basement Complex of Nigeria. In: Dessauvagie T. F. J. and Whiteman A. J. (Eds.): African Geology. Ibadan Univ. Press, Nigeria, 67-99.

Palacky G. J., 1987: Resistivity characteristics of geologic targets. In: Nabighian M. N. (Ed.): Electromagnetic Methods in Applied Geophysics - Theory, 1, Society of Exploration Geophysicists, Tulsa, OK, 53-129.

Park C. G., Helliwell R. A., 1978: Magnetosphere effects of power line radiation. Science, 200, 4343, 727-730, doi: 10.1126/science.200.4343.727.

Pearson W. C., Skinner C. M., 1982: Reduction-to-the-pole of low latitude magnetic anomalies, 52nd Ann. Internat. Mtg., Sot. Expl. Geophys., Expanded Abstracts, 356-358, doi: 10.1190/1.1826974.

Rahaman M. A., 1988: Recent advances in the study of the basement complex of Nigeria. In: Oluyide P. O. et al. (Eds.): Precambrian Geology of Nigeria. Geological Survey of Nigeria Publication, Kaduna, 11-43.

Smith R., 2014: Electromagnetic Induction Methods in Mining Geophysics from 2008 to 2012. Surveys in Geophysics, 35, 1, 1230-156.

Sundararajan N., Rameshbabu V., Prasad N. S., Srinivas Y., 2006: VLFPROS-A MATLAB code for processing of VLF-EM data. Computers \& Geosciences, 32, 18061813, doi: 10.1016/j. cageo.2006.02.021.

Zhang H., Marangoni Y. R., 2013: A new RTP method via nonlinear thresholding at low latitudes. 13th International Congress of the Brazilian Geophysical Society \& EXPOGEF, Rio de Janeiro, Brazil, 26-29 August 2013, 337-339, doi: 10.1190/sbgf2 013-072. 